\title{
Fibroblast Growth Factor 10 Enhances Equine 0ocyte Maturation and Blastocyst Formation In Vitro
}

\author{
Reyes-Perea $\mathrm{AD}^{1,2}$, Aguila $\mathrm{L}^{3}$, Smith $\mathrm{L}^{3}$, Diaw $\mathrm{M}^{2 *}$ and Guerrero Netro $\mathrm{HM}^{1 *}$ \\ ${ }^{1}$ Department of Reproduction, Facultad de Medicina Veterinaria y Zootecnia, UNAM, Mexico \\ ${ }^{2}$ Department of Clinical Sciences, Faculty of Veterinary Medicine, Canada \\ ${ }^{3}$ Centre de recherche en reproduction et fértilité (CRRF), Canada
}

*Corresponding author: Mouhamadou Diaw, Department of Clinical Sciences, Faculty of Veterinary Medicine, University of Montreal, 3200 Sicotte St Hyacinthe, J2S 7C6 Quebec, Canada

Hilda Guerrero Netro, Department of Reproduction, Faculty of Veterinary Medicine and Zootechnics, National Autonomous

University of Mexico, University City, Mexico City, 04510, Mexico

ARTICLE INFO

Received: 崫 August 23, 2019

Published: 蔧 August 29, 2019

Citation: Reyes-Perea AD, Aguila L, Smith L, Diaw M, Guerrero Netro HM. Fibroblast Growth Factor 10 Enhances Equine Oocyte Maturation and Blastocyst Formation In Vitro. Biomed J Sci \& Tech Res 21(1)-2019. BJSTR. MS.ID.003534.

Keywords: Oocyte; In Vitro Maturation; Intracytoplasmic Sperm Injection; FGF 10; Embryo; Equine

\begin{abstract}
Oocyte maturation to the metaphase II of meiosis is a critical step for successful in vitro embryo production in domestic species, but for equine, this technique needs improvement. Fibroblast growth factors (FGFs), including FGF10, have a positive effect on in vitro oocyte maturation in different species but to our knowledge, their effects have never been studied in the mare. In this study, we investigated the effects of FGF10 on equine oocyte maturation and blastocyst formation. Oocytes, cumulus, and granulosa cells were collected, and the levels of the FGF10 receptor FGFR2B were measured by real-time PCR. Cumulus-oocyte complexes (COCs) collected from slaughterhouse-derived equine ovaries were exposed to basal medium containing $0,0.1,0.5$, and $1 \mathrm{ng} / \mathrm{mL}$ of FGF10. After $36 \mathrm{~h}$ of maturation, the oocytes were stained to evaluate nuclear maturation and determinate optimal FGF10 concentration. Control oocytes and those treated with the optimal FGF10 concentration were fertilized by intracytoplasmic sperm injection and cultured in vitro to the blastocyst stage. The FGFR2B mRNA was present in oocytes, cumulus, and granulosa cells. After in vitro maturation, $38 \%$ of COCs from the control and $0.1 \mathrm{ng} / \mathrm{mL}$ FGF10 groups reached metaphase II compared to $30 \%$ and $15 \%$ of COCs treated with $0.5 \mathrm{ng} / \mathrm{mL}$ and $1 \mathrm{ng} / \mathrm{mL}$ FGF10, respectively. After fertilization, blastocyst development rates were significantly different between the control group (7.28\%) and the $0.1 \mathrm{ng} / \mathrm{mL}$ FGF10 group (20.91\%). Thus, we conclude that the addition of $0.1 \mathrm{ng} /$ mL FGF10 to equine oocyte maturation media markedly improves their developmental competence to form blastocysts after fertilization.
\end{abstract}

\section{Introduction}

In cattle, the systems for oocyte in vitro maturation (IVM), in vitro fertilization (IVF), and in vitro production of bovine embryos are well established [1]. However, the use of IVM and IVF are limited in the horse, with intracytoplasmic sperm injection (ICSI) being the only repeatable and effective IVF method currently available [2]. Equine IVM rates vary between $30 \%$ to $60 \%$, while IVF rates are around $4 \%$ to $33 \%$, with only two foals having been born from both techniques $[1,3,4]$. In horses, the hormonal requirements during oocyte maturation remain unknown, and physiological patterns of follicle development and ovulation differ substantially from those in other species [3].

During follicle development, the oocyte achieves developmental competence by resuming meiosis and acquiring the capacity to be fertilized [5]. Oocyte developmental competence is regulated within the follicle by members of the fibroblast growth factor (FGF) family [6]. The FGF family includes 23 different polypeptides that signal through members of the fibroblast growth factor receptor (FGFR) family of transmembrane tyrosine kinase receptors (FGFR1-4) 
and act as paracrine factors during cell development [7]. Although various studies have demonstrated the importance of FGFs during reproduction, FGF2, also known as basic FGF, has received the most attention due to its role in follicle development, wherein it stimulates estradiol secretion, elevates the number of luteinizing hormone receptors [8], promotes granulosa cell proliferation, and increases the percentage of mature oocytes $[9,10]$. FGF10 mRNA transcripts and protein have been detected in human granulosa cells, as well as in oocytes from antral follicles. In bovine, FGF10 is expressed predominantly in theca cells, but FGF10 protein and mRNA transcripts have also been found in oocytes from antral follicles. FGF10 signals through the activation of the FGFR1B and FGFR2B receptors, which are both localized in cumulus cells. The FGFR2B mRNA has also been detected in granulosa cells, suggesting its possible contribution to oocyte maturation $[8,11,12]$.

In goats, FGF10 maintains the morphological integrity of preantral follicles and stimulates the growth of activated follicles in vitro [13] roviding FGF10 to bovine cumulus-oocyte complexes (COCs) during IVM significantly increases cumulus expansion, oocyte maturation, and the percentage of embryos at the 8-16cell stage on day 3 as well as at the blastocyst stage on day 7 . The addition of an anti-FGF10 IgG during bovine oocyte maturation has been shown to reduce the blastocyst rate and limit cumulus expansion, further supporting the importance of FGF10 during oocyte maturation [6].

In horses, the process by which an oocyte reaches meiotic maturation and developmental competence both in vivo and in vitro remains unknown. Taking into account the importance of FGF10 during oocyte maturation in several species, we hypothesized that the addition of FGF10 to the IVM medium might increase the percentage of mature equine oocytes. Therefore, this work was aimed at determining whether FGF10 enhances oocyte maturation and the development to the blastocyst stage after ICSI in horses.

\section{Material and Methods}

\section{Ovary and Oocyte Recovery}

Ovaries were obtained at a local slaughterhouse, placed in an insulated container, and transported at room temperature $\left(\sim 22^{\circ} \mathrm{C}\right)$ to a laboratory at the CRFF, Université de Montréal, Canada. To collect the cumulus-oocyte-complexes (COCs), all visible nonpathological follicles $<25 \mathrm{~mm}$ in diameter were scraped using a needle attached to a sterile collection bottle via a tube and a vacuum pump set to aspirate approximately $20 \mathrm{~mL}$ of fluid per minute. The needle and the tube were intermittently flushed with a commercial oocyte recovery medium (Equi Pro OPU Recovery Medium; MOFA Global, Verona, WI, USA). After all the follicles had been aspirated, the content of the bottle was filtered, and COCs were identified and selected using a dissecting microscope. Selected COCs were cultured in a $1 \mathrm{~mL}$ borosilicate glass vial (Thermo Fisher Scientific, Waltham, MA, USA) containing a holding medium (Vigro Holding Plus, Vetoquinol, Pullman, WA, USA) at room temperature $\left(\sim 22^{\circ} \mathrm{C}\right)$ overnight $(\sim 15 \mathrm{~h})$ as previously described by Diaw et al. [14].

\section{In vitro Maturation (IVM)}

Random groups of 10 COCs were washed twice in maturation medium (M199 medium with Earle's salts; Sigma Chemical Co., St. Louis, MO, USA) supplemented with $25 \mu \mathrm{g} / \mathrm{mL}$ gentamicin (Gibco), $10 \%$ FBS and $5 \mathrm{mU} / \mathrm{mL}$ FSH (Sioux Biochemicals, Sioux Center, IA, USA). COCs were cultured at $37.5^{\circ} \mathrm{C}$ in an humidified atmosphere of $5 \% \mathrm{CO}_{2}$ for $36 \mathrm{~h}$ under light mineral oil (Sage, In-Vitro Fertilization, Inc., Trumbull, CT, USA) in $100 \mu \mathrm{L}$ droplets of maturation medium containing different concentrations of FGF10 (0, 0.1, 0.5 and1 ng/ mL; Sigma Aldrich, MO, USA).

\section{Cumulus Cells Expansion}

After the IVM the COCs were evaluated and classified according to the number of layers as being expanded 1 (having a tight, complete compact cumulus with a distinct, smooth hillock), expanded 2 (having a granular or expanded cumulus with 2-5 layers of cells), expanded 3 (having a granular or expanded cumulus with 5 or more layers of cells), or denuded (having a partial cumulus or only corona radiata present), as previously described by Hinrichs et al. [15].

\section{Chromatin Evaluation}

Oocytes were denuded of the cumulus cells using a fine bore pipette in a solution of Hank's salt supplemented with $0.5 \%$ hyaluronidase. Denuded oocytes were fixed for a minimum of 12 $\mathrm{h}$ in a buffered formalin solution, stained with Hoechst 33258, and mounted on slides using a Perma Fluor Aqueous Mounting Medium (Thermo Fisher Scientific, Waltham, MA, USA). A cover slip with petroleum jelly applied on the corners was placed around the oocytes, and the edges were sealed with fingernail polish. The chromosomal arrangement, as well as visualization of the polar body, was performed using an Axio Observer.Z1 motorized Basic (Zeiss) fluorescence microscope with a 365-nm excitation filter driven by Zen software Pro 2012. The chromatin configuration of the oocytes was classified as either germinal vesicle (GV), metaphase I, metaphase II, or degenerating, as previously described by Hinrichs et al. [16].

\section{Intracytoplasmic Sperm Injection (ICSI)}

After IVM using either 0 or $0.1 \mathrm{ng} / \mathrm{mL}$ FGF10, oocytes were denuded by pipetting in the presence of $10 \%$ FBS supplemented with $1 \mathrm{mg} / \mathrm{mL}$ hyaluronidase and classified according to the presence of the first polar body. Oocytes with the first polar body were assigned as being mature and were used for ICSI. Spermatozoa, previously stored in liquid nitrogen, were thawed for $1 \mathrm{~min}$ in $35.8{ }^{\circ} \mathrm{C}$ water, added to a discontinuous gradient of $45 \%$ over $90 \%$ BoviPure (Nidacon Laboratories AB, Göthenberg, Sweden), and centrifuged at $600 \times \mathrm{g}$ for $5 \mathrm{~min}$. The supernatant containing the cryoprotectant and dead spermatozoa was discarded, and the pellet was then resuspended in $1 \mathrm{~mL}$ of modified Tyrode's lactate (TL) and centrifuged at $300 \times \mathrm{g}$ for $2 \mathrm{~min}$. ICSI was performed according to the standard 
protocol described by Águila et al. [16] on the stage of a Nikon Ti-S inverted microscope (Nikon Canada Inc., Mississauga, ON, Canada) fitted with Narishige micromanipulators (Narishige International US Inc., Amityville NY, USA) and a Piezo PMM 150HJ/FU (Prime Tech Ltd., Ibaraki, Japan). After ICSI, oocytes were washed at least three times and cultured in F12 media supplemented with $10 \%$ FBS.

\section{In vitro Embryo Culture}

For culture, groups of five embryos were placed in droplets $(10 \mu \mathrm{L})$ of DMEM/F12 media supplemented with 10\% FBS, under embryo-tested mineral oil and incubated at $38.5^{\circ} \mathrm{C}$ in an atmosphere of $6.5 \% \mathrm{CO}_{2}, 5 \% \mathrm{O}_{2}$, and $88.5 \% \mathrm{~N} 2$ at $100 \%$ humidity $[17,18]$ Embryos were transferred to new $20 \mu \mathrm{l}$ droplets of the same media at $72 \mathrm{~h}(10 \mu \mathrm{L})$ and $120 \mathrm{~h}$ post-fertilization. Blastocyst development was examined on days 7 to 11 post-fertilization. Cleavage rate was recorded at $72 \mathrm{~h}$ (day 3 ) of culture (ICSI = day 0 ). To determine the blastocyst rate, the embryos were cultured and evaluated from day 7 to 11 (264 h). Blastocysts were recovered and fixed in a buffered formalin solution, stained with Hoechst 33258, and mounted using Perma Fluor Aqueous Mounting Medium (Thermo Fisher Scientific, Waltham, MA, USA) on a cover slip. Evaluation of embryo quality and development was performed using an Axio Observer Z1 motorized Basic (Zeiss) fluorescence microscope with a 365-nm excitation filter driven by Zen software Pro 2012. Embryo evaluation was performed according to Pomar et al. [18].

\section{Total RNA Extraction, RT-PCR, and Real-Time PCR Quantification}

Total RNA was isolated from granulosa cells using a PicoPure RNA Isolation Kit (Thermo Fisher Scientific) according to the manufacturer's instructions. Reverse transcription was performed using 200 ng of total RNA and a Super Script ${ }^{\circledR}$ VILO cDNA Synthesis Kit. Real-time PCR was performed in a $15 \mu \mathrm{L}$ reaction volume containing $1 \mu \mathrm{L}$ of cDNA and $2 \times$ Power SYBR Green PCR Master Mix on a CFX-96 Real-Time PCR Detection System (Bio-Rad Laboratories Ltd., Hercules, CA, USA).
Primers specific for the horse FGF10 receptor FGFR2B were: Forward: 5'-AAGACCACAAATGGGCGACT-3', and Reverse: 5'-ACATCAACACCCCGAAGGAC-3'. The thermal cycling parameter used to amplify each transcript was $3 \mathrm{~min}$ at $95^{\circ} \mathrm{C}, 40$ cycles of $15 \mathrm{~s}$ at $95^{\circ} \mathrm{C}, 30 \mathrm{~s}$ at $59^{\circ} \mathrm{C}$, and $30 \mathrm{~s}$ at $72^{\circ} \mathrm{C}$. Melting curve analyses were performed to verify product identity, and the novel amplicons were sequenced to verify authenticity. Samples were run in triplicate, and the three replicates for each cell type were run on the same plates.

\section{Statistical Analysis}

All experiments were performed in triplicate. The effect of different doses of FGF10 on oocyte maturation was tested using an analysis of variance (ANOVA) and means from each replicate were compared with the Tukey-Kramer HSD. Statistical analyses used arcsin-transformed percentage data generated from each replicate (experimental unit $=$ average percentage within each replicate) Percentage of data were graphed using non-transformed values.

\section{Results}

\section{FGF10 Receptor FGFR2B Expression in Ovarian Cells}

The expression levels of the mRNA encoding FGF2B were measured in the oocyte, cumulus, and granulosa cells from the antral follicles, resulting in Ct values of 31,35 , and 33, respectively. Messenger RNA encoding FGFR2B was detected in extracts of equine oocytes, cumulus, and granulosa cells obtained from abattoir ovaries. Average Cq values were of 31 for oocytes, 35 for cumulus cells, and 33 for granulosa cells.

\section{COC Cumulus Cells Expansion}

A total of 569 equine oocytes were used and evaluated in this study. For the first experiment (n: 269), the respective data of cumulus cell-enclosed oocytes that attained cumulus expansion $(\%$ of expansion and LS means \pm SEM) in the four different treatments were: $29.11 \% \pm 8.18$ for the control $(0 \mathrm{ng} / \mathrm{mL}) ; 30.66 \% \pm 12.33$ for $0.1 \mathrm{ng} / \mathrm{mL} ; 28.2 \% \pm 22.49$ for expanded $0.5 \mathrm{ng} / \mathrm{mL}$; and $42.44 \% \pm$ 22.28 for $1 \mathrm{ng} / \mathrm{mL}$ (Table 1 ).

Table 1: The percentage of cumulus cells complexes (COCs) that reach the stage of expanded 1, 2 and 3 or denuded after $36 \mathrm{~h}$ of in vitro maturation for the control group $(0 \mathrm{ng} / \mathrm{mL})$ or the treatments $0.1 \mathrm{ng} / \mathrm{mL}, 0.5 \mathrm{ng} / \mathrm{mL}$ or $1 \mathrm{ng} / \mathrm{mL}$, however there was no significant difference between groups $(\mathrm{P}>0.05)$.

\begin{tabular}{|c|c|c|c|c|}
\hline \multicolumn{5}{|c|}{ Expansion Grade and Number of Oocytes (\% of Expansion and Ls Means \pm SEM) } \\
\hline Treatment & Denude & $\mathbf{1}$ & $\mathbf{2}$ & $\mathbf{3}$ \\
\hline $0 \mathrm{ng} / \mathrm{mL}$ & $2(4.8 \% \pm 8.49)$ & $6(13.04 \% \pm 17.64)$ & $27(56.66 \% \pm 11.54)$ & $14(29.11 \% \pm 8.18)$ \\
\hline $0.1 \mathrm{ng} / \mathrm{mL}$ & $2(6.4 \% \pm 4.92)$ & $3(6.6 \% \pm 8.44)$ & $28(57.33 \% \pm 15.88)$ & $15(30.66 \% \pm 12.33)$ \\
\hline $0.5 \mathrm{ng} / \mathrm{mL}$ & $1(2.8 \% \pm 4.02)$ & $4(2.8 \% \pm 12.58)$ & $31(62 \% \pm 23.87)$ & $14(28.2 \% \pm 22.49)$ \\
\hline $1 \mathrm{ng} / \mathrm{mL}$ & $2(4.6 \% \pm 4.92)$ & $2(4.6 \% \pm 4.92)$ & $17(47.55 \% \pm 23.13)$ & $21(42.44 \% \pm 22.28)$ \\
\hline
\end{tabular}

\section{COC in vitro Maturation}

The effect of FGF10 on oocyte maturation was initially assessed using different doses of FGF10. The different doses of FGF10 used did not significantly change the percentage of oocytes that reached intermediary phases, such as telophase I or metaphase II after $36 \mathrm{~h}$ of maturation. However, exposure to $0.1 \mathrm{ng} / \mathrm{mL}$ FGF10 tended $(\mathrm{P}>$ $0.05)$ to increase the percentage of oocytes in metaphase II (58.5\%) when compared to the control (38.9\%) (Figure 1). 


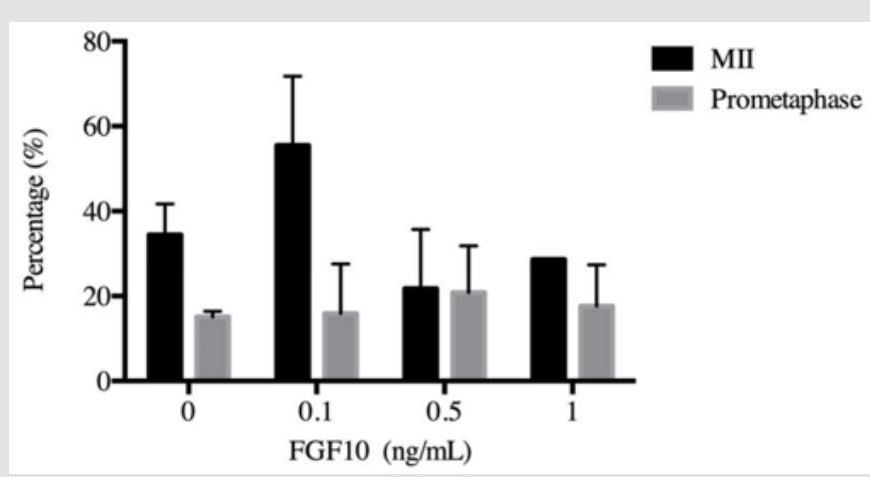

Figure 1: The percentage of the oocytes that reached the metaphase II (MII) determined after $36 \mathrm{~h}$ of in vitro maturation. The control group $(0 \mathrm{ng} / \mathrm{mL}$ ) and the $0.1 \mathrm{ng} / \mathrm{mL}$ group had a similar percentage of oocytes reaching the MII stage (34.42\% vs. $55.47 \% ; \mathrm{P}>0.05)$. The $0.1 \mathrm{ng} / \mathrm{mL}$ group had the same number of oocytes in prometaphase II as that in the control group (15.08\% vs. $15.87 \%$; P > 0.05). For the $0.5 \mathrm{ng} / \mathrm{mL}$ and $1 \mathrm{ng} / \mathrm{mL}$ groups, the percentage of oocytes in MII was lower compared to that in the control group $(21.76 \%$ vs. $28.61 \% ; \mathrm{P}>0.05)$.

In a second experiment, a new set of oocytes were used for ICSI using the optimal dose determined in the first experiment $(0.1 \mathrm{ng} / \mathrm{mL})$ and the control. Supplementation of the maturation media with $0.1 \mathrm{ng} / \mathrm{mL}$ FGF10 increased the percentage of oocytes in metaphase II (34.76\%) when compared to the control group $(28.73 \%)(P<0.05)$. Despite this, the number of degraded and dead oocytes did not change with the addition of FGF10 when compared to the control (Figure 2).

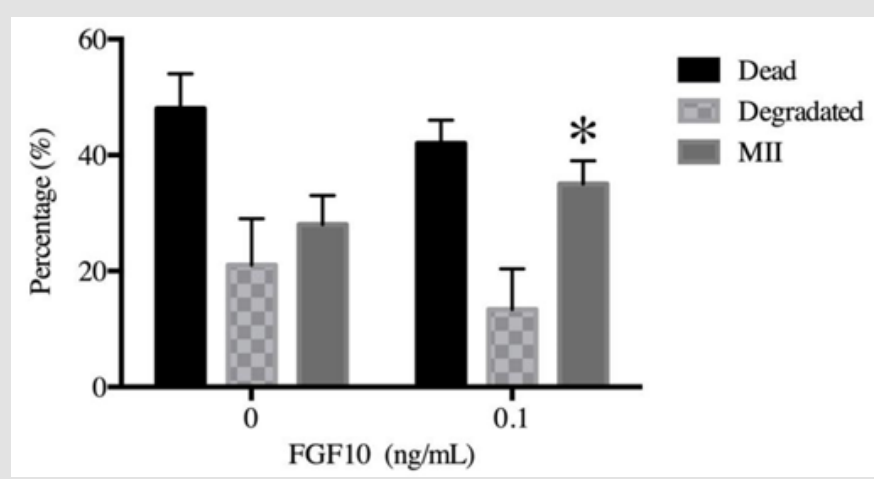

Figure 2: A new batch of oocytes was matured in either the absence of FGF10 ( $0 \mathrm{ng} / \mathrm{mL}$, control) or in the presence of $0.1 \mathrm{ng} /$ mL FGF10 as the optimal concentration. After $30 \mathrm{~h}$ of maturation, the oocytes were denuded with hyaluronidase and ICSI was then performed. The control $(0 \mathrm{ng} / \mathrm{mL})$ and the $0.1 \mathrm{ng} / \mathrm{mL}$ FGF10 groups were evaluated for the presence of the first polar body (metaphase II/MII) and also for the presence of dead or deformed oocytes after maturation. The graph shows that the $0.1 \mathrm{ng} / \mathrm{ml}$ FGF10 group had a higher percentage of oocytes in MII $(34.76 \%)$ compared to that in control $(28.73 \%)(\mathrm{P}<0.05)$; additionally, it had decreased numbers of dead ( $47.7 \%$ vs. $42 \%)$ and degraded oocytes (21.03\% vs. $13.4 \% ; \mathrm{P}>0.05)$.

\section{Embryo Cleavage and Blastocyst Development}

The cleavage rate was evaluated on day 3 after ICSI. Cleavage at day 3 was $46 \%$ in the control group versus $60 \%$ in the presence of
$0.1 \mathrm{ng} / \mathrm{mL}$ FGF10 (P > 0.05), but this difference was not statistically significant. In contrast, the addition of $0.1 \mathrm{ng} / \mathrm{mL}$ FGF10 significantly increased $(\mathrm{P}<0.05)$ the percentage of cleaved embryos that formed blastocysts on day 7 when compared to the control (Figure 3).

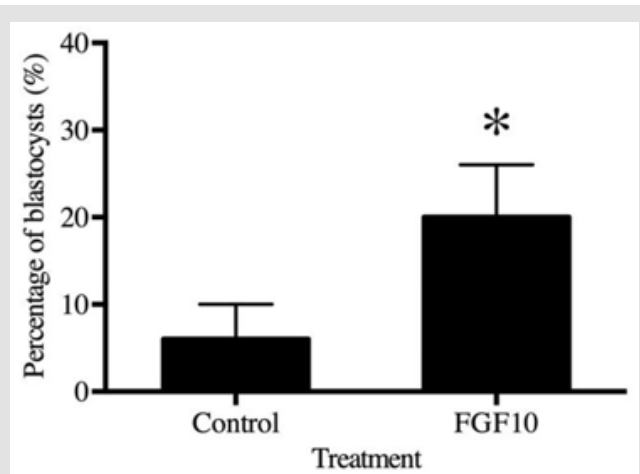

Figure 3: The blastocysts stage is expected to occur from day 7 till day 11 . The $0.1 \mathrm{ng} / \mathrm{mL}$ FGF10 treatment group showed a significant increase in the number of blastocysts at day $11(19.6 \%)$ compared to that in the control group $(6.6 \%)$ on the same day $(\mathrm{P}<0.05)$. 


\section{Discussion}

To the best our knowledge, the present study reports, for the first time, the effects of FGF10 on equine oocyte maturation in vitro. Our results demonstrate that FGF10 plays a role in the progression of meiotic maturation and in the acquisition of developmental competence to reach the blastocyst after ICSI.FGF10 is a theca and granulosa cell-derived factor, and as the follicle grows and reaches the antral phase, oocytes can also secrete FGF10 [8]. During in vitro maturation, oocytes do not have access to theca, and granulosa cell-derived factors, including FGF10. Therefore, we hypothesized that oocytes require the addition of the theca-derived factor FGF10 to reach developmental and meiotic competence in vitro. FGF10 is known to signal mainly through FGFR2B, which is present in both cumulus cells and the granulosa cells of growing follicles in cattle and human [8,11].Our results demonstrate the presence of the mRNA encoding FGFR2B in granulosa cells, cumulus cells, and oocytes as previously reported in other species, suggesting a potential role for FGF10 during horse follicular development [12].

In our experiments, the addition of FGF10 resulted in enhanced cumulus expansion; this effect has previously been reported in bovine COCs, in which an up-regulation of PTGS2 expression and glucose uptake by cumulus cells leads to an increase in the hyaluronic acid substrate that is necessary for cumulus cell expansion [19]. Nevertheless, the mechanism through which FGF10 promotes cumulus cell expansion in horse oocytes remains to be elucidated.

Different doses of FGF10 resulted in no significant differences in the percentage of oocytes that extruded the first polar body. However, in a different set of experiments, $0.1 \mathrm{ng} / \mathrm{mL}$ FGF10 decreased the number of dead oocytes and significantly increased the percentage of oocytes in metaphase II compared to those in control, as previously reported by Pomini Pinto et al. [20]. These changes in maturation rates with the same base medium were previously reported by Hinrichs et al. [3]. One possible reason for the differences between the two experiments could be related to the quality of the oocytes; the first experiment was performed using oocytes obtained at the beginning of the breeding season when mares are in the spring transition, whereas the ICSI experiment was performed in the middle of the breeding season, which leads to better oocyte quality [1]. However, extrusion of the first polar body is not considered a significant marker of meiotic and developmental competence in horses. The quantity of lipids present in the oocyte makes it difficult to differentiate nuclear structures using a microscope, but as there are no other reliable markers for maturation, oocytes showing the presence of the first polar body were selected for ICSI [20].

After the ICSI, FGF10 treated oocytes showed higher blastocyst developmental potential compared to the control; this result might be related to the ability of FGF10 to increase the relative abundance of developmental genes in bovine oocytes, such as COX2, CDX2, and PLAC8 [21].While FGF10 is known for its role in embryo development it has never been associated with an increase in the blastocyst rate; this finding opens new opportunities for future research in the relationship of FGF10 with oocyte maturation and embryo development.

\section{Conclusion}

In summary, this study presents a novel role for FGF10 in oocyte maturation. The addition of FGF10 to maturation media results in a higher percentage of oocytes in metaphase II and a higher number of blastocysts. Additionally, the finding regarding the expression of the FGF10 receptor FGFR2B in the oocyte, cumulus, and granulosa cells allows for a better understanding of the role of FGF10 during COC maturation, reinforcing the idea that FGF10 may be useful in improving IVM protocols in horses.

\section{Declaration of interests}

The authors declare that there are no conflicts of interest that could be perceived as prejudicing the impartiality of the research reported.

\section{Funding Sources}

This work was supported by the Equine health fund from the Faculty of Veterinary Medicine of the Université de Montréal supported by Zoetis, PAEP-Universidad Nacional Autónoma de México, and CONACYT México.

\section{Acknowledgment}

We thank Dr. Christopher Price and Laurianne Relav for their support of this project.

\section{References}

1. Dellaquila ME, Fusco S, Lacalandra GM, Maritato F (1996) In vitro maturation and fertilization of equine oocytes recovered during the breeding season. Theriogenology 45(3): 547-560.

2. Rader K, Choi YH, Hinrichs K (2016) Intracytoplasmic sperm injection, embryo culture, and transfer of in vitro-produced blastocysts. Vet Clin North Am Equine Pract 32(3): 401-413.

3. Hinrichs K, Love CC, Brinsko SP, Choi YH, Varner DD (2002) In vitro fertilization of in vitro-matured equine oocytes: effect of maturation medium, duration of maturation, and sperm calcium ionophore treatment, and comparison with rates of fertilization in vivo after oviductal transfer. Biol Reprod 67(1): 256-262.

4. Merlo B, Iacono E, Bucci D, Spinaci M, Galeati G, et al. (2016) Betamercaptoethanol supplementation of in vitro maturation medium does not influence nuclear and cytoplasmic maturation of equine oocytes. Reprod Domest Anim 51(6): 992-996.

5. Conti M, Franciosi F(2018) Acquisition of oocyte competence to develop as an embryo: integrated nuclear and cytoplasmic events. Hum Reprod Update 24(3): 245-266.

6. Zhang K, Hansen PJ, Ealy AD (2010) Fibroblast growth factor 10 enhances bovine oocyte maturation and developmental competence in vitro. Reproduction 140(6): 815-826.

7. Yun YR, Won JE, Jeon E, Lee S, Kang W, et al. (2010) Fibroblast growth factors: biology, function, and application for tissue regeneration. J Tissue Eng 2010: 218142. 
8. Buratini J, Pinto MG, Castilho AC, Amorim RL, Giometti IC, et al. (2007) Expression and function of fibroblast growth factor 10 and its receptor fibroblast growth factor receptor 2B, in bovine follicles. Biol Reprod 77(4): 743-750.

9. Cao M, Nicola E, Portela VM, Price CA (2006) Regulation of serine protease inhibitor-E2 and plasminogen activator expression and secretion by follicle stimulating hormone and growth factors in nonluteinizing bovine granulosa cells in vitro. Matrix Biol 25(6): 342-354.

10. Mondal S, Mor A, Reddy IJ, Parameswaragupta PS (2015) Effect of fibroblast growth factor 2 (FGF2) and insulin transferrin selenium (ITS) on in vitro maturation, fertilization and embryo development in sheep. Braz Arch Biol Technol 58(4): 521-525.

11. Oron G, Fisch B, Zhang XY, Gabbay Benziv R, Kessler Icekson G, et al. (2012) Fibroblast growth factor 10 in human ovaries. Reprod Biomed Online 25(4): 396-401

12. Price CA (2016) Mechanisms of fibroblast growth factor signaling in the ovarian follicle. J Endocrinol 228(2): R31-43.

13. Chaves RN, Lima Verde IB, Celestino JJ, Duarte AB, Alves AM, et al. (2010) Fibroblast growth factor-10 maintains the survival and promotes the growth of cultured goat preantral follicles. Domest Anim Endocrinol 39(4): 249-258.

14. Diaw M, Salgado RM, Canesin HS, Gridley N, Hinrichs K (2018) Effect of different shipping temperatures (approximately 22 degrees C vs. approximately 7 degrees $\mathrm{C}$ ) and holding media on blastocyst development after overnight holding of immature equine cumulusoocyte complexes. Theriogenology 111: 62-68.

\section{ISSN: 2574-1241}

DOI: 10.26717/BJSTR.2019.21.003534

Diaw M, Guerrero Netro HM. Biomed J Sci \& Tech Res

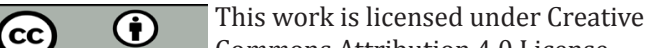
Commons Attribution 4.0 License

Submission Link: https://biomedres.us/submit-manuscript.php
15. Hinrichs K, Choi YH, Love LB, Varner DD, Love CC (2018) Chromatin configuration within the germinal vesicle of horse oocytes: changes post mortem and relationship to meiotic and developmental competence. Biol Reprod 72(5): 1142-1150.

16. Águila L, Zambrano F, Arias ME, Felmer R (2017)Sperm capacitation pretreatment positively impacts bovine intracytoplasmic sperm injection. Mol Reprod Dev 84(7): 649-659.

17. Nivet AL, Bunel A, Labrecque R, Belanger J, Vigneault C, et al. (2012) FSH withdrawal improves developmental competence of oocytes in the bovine model. Reproduction 143(2):165-171.

18. Pomar FJ, Teerds KJ, Kidson A, Colenbrander B, Tharasanit T, et al. (2005) Differences in the incidence of apoptosis between in vivo and in vitro produced blastocysts of farm animal species: a comparative study. Theriogenology 63(8): 2254-2268.

19. Webb, R, Buratini, J, Hernandez Modrano JH, Gutiérrez CG, Campbell BK (2016) Follicle development and selection: past, present and future. Animal Reprod 13(3): 234-249.

20. Pomini Pinto RF, Fontes PK, Loureiro B, Sousa Castilho AC, Sousa Ticianelli J, et al. (2015) Effects of FGF10 on bovine oocyte meiosis progression, apoptosis, embryo development and relative abundance of developmentally important genes in vitro. Reprod Domest Anim 50(1): 84-90.

21. Hinrichs K, Schmidt AL, Friedman PP, Selgrath JP, Martin MG (1993) In vitro maturation of horse oocytes: characterization of chromatin configuration using fluorescence microscopy. Biol Reprod 48(2): 363370 .

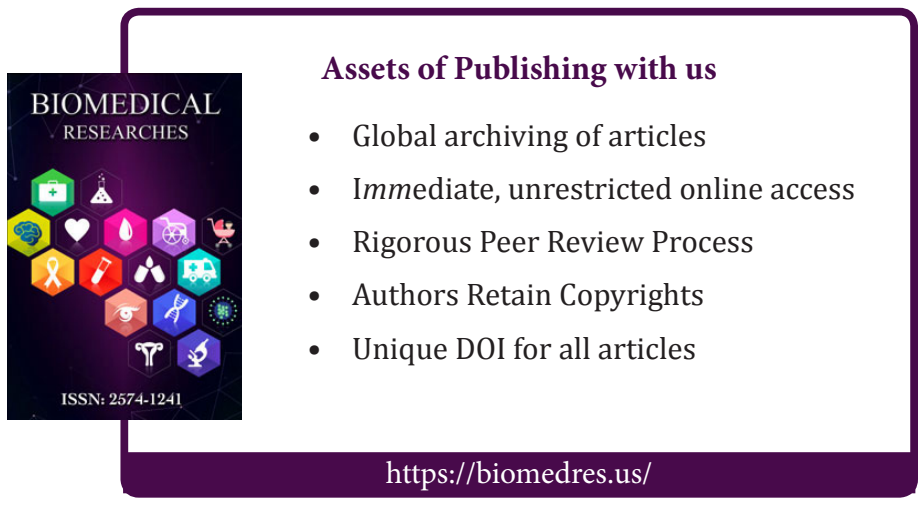

